\title{
Ultrasound Investigation of Dorsal Neck Muscle Deformation During a Neck Rotation Exercise
}

Johan E. Bjorkkvist, Gunnel Peterson and Anneli Peolsson

The self-archived postprint version of this journal article is available at Linköping University Institutional Repository (DiVA):

http://urn.kb.se/resolve?urn=urn:nbn:se:liu:diva-172960

N.B.: When citing this work, cite the original publication.

Bjorkkvist, J. E., Peterson, G., Peolsson, A., (2020), Ultrasound Investigation of Dorsal Neck Muscle Deformation During a Neck Rotation Exercise, Journal of Manipulative and Physiological

Therapeutics, 43(9), 864-873. https://doi.org/10.1016/j.jmpt.2019.12.011

Original publication available at:

https://doi.org/10.1016/j.jmpt.2019.12.011

Copyright: Elsevier

http://www.elsevier.com/

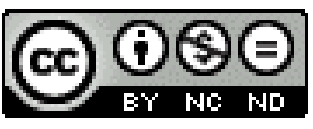


ULTRASOUND INVESTIGATION OF DORSAL NECK MUSCLES DEFORMATION DURING A NECK ROTATION EXERCISE

Johan Björkkvist1, Gunnel Peterson2, 3, Anneli Peolsson3

1Eskilstuna Fysiocenter, Region Sörmland, Eskilstuna, Sweden

2Centre for Clinical Research Sörmland, Uppsala University, Eskilstuna, Sweden

3Department of Medical and Health Sciences, Physiotherapy, Linköping University, Linköping, Sweden

Corresponding author: Gunnel Peterson, Department of Medical and Health Sciences, Physiotherapy, Linköping University, SE-581 83 Sweden. Email: gunnel.peterson@liu.se, phone +46722100901 , fax +4615054603 


\section{Abstract}

Objectives: Neck-specific exercise can reduce neck pain and increase function, but information on how different neck muscle layers are activated during neck exercises is scarce. The aim of this study was to investigate deformation and deformation rate in five dorsal neck muscles and correlation between these muscles during a loaded dynamic exercise used in clinical practice.

Methods: Deformation and deformation rate were investigated in five dorsal right sided neck muscles in twenty individuals without neck pain using ultrasonography and speckle tracking analyses. Repeated measures ANOVA was used to measure differences between the muscles, and correlations between neck muscles were analyzed with Kendall's tau. Results: Deformation in left (contralateral) rotation showed significant differences between the muscles $(p=0.01)$ with higher deformation of the semispinalis capitis muscle compared with the trapezius muscle $(p=0.02)$. There were no significant differences between the five neck muscles in right (unilateral) rotation $(p=0.46)$. There were significant differences in deformation rate between muscles in both right and left rotation $(\mathrm{p}<0.01)$. The trapezius muscles have the lowest deformation rate in right rotation $(\mathrm{p}<$ 0.01). In left rotation the trapezius and multifidus muscles showed lower deformation rates compared with most of the other muscles $(\mathrm{p}<0.03)$. Almost all muscles were correlated in both deformation and deformation rate.

Conclusion: The quadrupled standing loaded dynamic neck exercise seems to activate all the investigated neck muscles with a tendency to more activation of semispinalis capitis. In future studies, individuals with neck pain should be investigated. Key index terms: Neck Muscles; Ultrasonography; Motor skills; Exercise. 


\section{Introduction}

Neck pain occurs frequently in the general population, ${ }^{1,2}$ and up to $60 \%$ of people with neck pain will have recurrent problems after the first episode. ${ }^{3}$ The Global Burden of Disease Study classified 345 diseases in 2017, and neck pain was the ninth top cause for females and 12th for males of years lived with disability. ${ }^{4}$ Neck pain is also an expensive cost for society as patients with back and/or neck pain have $85-182 \%$ more annual health care costs than people without pain. ${ }^{5}$ Impaired neck muscle function has been reported in individuals with neck pain ${ }^{6,7}$ and there is moderate evidence that neck-specific exercises have a positive effect ${ }^{8}$. The deep neck muscles contribute to control of intersegmental motion $^{9}$ while the most superficial muscles move the head. The purpose of specific neck exercise is to increase neuromuscular control, strengthen muscles and endurance, and increase physical capacity. ${ }^{10-12}$ The rotation exercise has been used as a test for neuromuscular control and as an exercise for increasing stability and strength. ${ }^{11,13,14}$ However, there is scarce information about how the different neck muscle layers are activated during neck exercises. ${ }^{15}$

Ultrasound can detect muscle deformation and deformation rate in deep muscles close to the spine and at the same time, deformation in more superficial muscle layers. Briefly, ultrasound echoes from small irregularities in the muscles form a unique speckle pattern and can serve as acoustic markers. This speckle can be followed frame-by-frame through the ultrasound images with speckle-tracking analyses and provides measurements of muscle deformation (elongation or shortening) and deformation rate (how fast the deformation occurs). ${ }^{16}$ Ultrasound with speckle tracking analyses provides measurements during activity and thereby improves knowledge of mechanical muscle function. ${ }^{17-22}$

To the authors' knowledge, no study has examined the interplay between muscles with real-time ultrasound images with speckle tracking analysis in a dynamic exercise for neck 
rotation. Thus, it is currently not known which muscles are trained in this exercise. Better insight of the deformation, deformation rate, and the interplay between dorsal neck muscles could help our understanding of which muscles are primarily targeted during specific neck rehabilitation. It could also generate hypotheses regarding effects on muscle coordination or effects of training in dynamic exercises used in future research in patients with neck pain.

The aim of this study was to investigate differences in deformation between different muscle layers in dorsal neck muscles and their interplay during a dynamic neck rotation exercise, specifically quadruped rotation training, in subjects with good neck health.

\section{Method}

\section{Design}

The study used a cross-sectional prospective study.

\section{Participants}

Twenty participants, eleven females and nine males (mean age 27.6, SD 7.28) were included in the study. Participant characteristics are presented in Table 1.

Participants were recruited by asking students and staff at the University of Linköping to participate voluntarily via bulk mail. They were informed of the purpose of the examination, the procedure of the test, and that no adverse effects were expected. The sample size was arbitrary as no study of deformation and deformation rate of dorsal neck muscles in rotation exercise had previously been conducted.

Inclusion criteria were no ongoing or history of neck pain defined as Visual Analogue Scale (VAS) (0-100 mm) less than $10 \mathrm{~mm}$ and less than $20 \%$ on Neck Disability Index Score (NDI) (0-100 \%) and no trauma to head or neck. Exclusion criteria were rheumatic 
illness, generalized myalgia, severe lower back pain, previous back surgery, and earlier back trauma.

The study was conducted according to the Declaration of Helsinki and was approved by the Ethics Committee at the Faculty of Health Sciences at a Linköping University in Sweden. The participants provided written and oral informed consent.

\section{Ultrasound imaging}

Ultrasound was recorded during the rotation exercise with a 14.0 $\mathrm{MHz}$ linear transducer (38 mm footprint) and US Vivid 9 Dimension (GE Healthcare, Horten, Norway) with high frame rate (78 frames/s) operated in B-mode, and a 2D US imaging system.

Data were collected by a medical engineer experienced in ultrasonography with assistance of a physiotherapist (PT) specializing in neck pain rehabilitation. The participants were in the quadruped position (i.e. on all fours), chin tucked in, and had slight cervicothoracic extension, with a thin rubber band (yellow Thera-Band; The Hygienic cooperation, Akron, USA) between hands and mouth (Fig. 1). The length of the rubber band was $2 \mathrm{x}$ the armlength of the participants. The participants were instructed visually and orally to conduct a head rotation $70^{\circ}$, first to the right and back to start position, release the rubber band and rest for 30 seconds and then conduct a rotation $70^{\circ}$ to the left. The lower cervical spine was in slight extension and chin tucked in. The participants' test position was corrected by the PT if needed.

The PT first identified the spinous process of the C4-vertebrae and marked it with a pen. The ultrasound transducer was positioned at the right side of the C4-level in transverse orientation. The spinous process was identified on imaging and the transducer was rotated $90^{\circ}$ in longitudinal direction. Ultrasound recording started with the neck in neutral position and ended when the head returned to neutral. Images of the dorsal cervical muscles, from most superficial to the deepest - the trapezius (Tr), splenius ( $\mathrm{Sp}$ ), 
semispinalis (Sca) capitis, semispinalis cervicis (Scer), and multifidus (Mf) muscles - (Fig

2) were recorded in real time during the dynamic exercise.

\section{Speckle tracking}

Ultrasound recordings of the dorsal neck muscles were analyzed with speckle-tracking post-process analysis. Speckle-tracking has been used to analyze changes in neck muscle deformation and deformation rate in dynamic neck extension and postural control of the neck, but never before in neck rotation. ${ }^{13,18,22-26}$ Five regions of interest (ROIs) were manually placed longitudinally $(10 \times 2 \mathrm{~mm})$ in the first frame of the video sequence (Fig. 2) and the ROI tracked the deformation frame by frame during the whole exercise. Analyses were performed by a PT with ten years' experience of ultrasound analysis. The speckle-tracking analysis was carried out in Multivariate Analysis of Congruent Images (MACI) ${ }^{17}$ and has been used in earlier research of dorsal neck muscles. ${ }^{18}$ Deformation of the muscles was defined as a change in length (shortening or elongation) calculated as the percentage change ( $\%$ deformation) from the original length. A positive value indicated an elongation of the muscles and a negative value indicated shortening of the muscles (Fig.

3). Deformation rate was defined as percentage of change of muscle length per second (\% deformation/s) presented as the root mean square (RMS). To assess muscle deformation, the areas on the deformation curves were calculated. Basis for the area calculation was the trapezoidal rule (Equation 1) where $\mathrm{A}$ is the area, $\mathrm{t}$ is time between samples and yn is the current ROI position at sample point $\mathrm{n}$. To handle intersections with the $0 \%$ line, the equation was modified. Linear interpolation was used to estimate additional sample points with adjusted t-values at intersections with the $0 \%$ line. Thereby, the area under and the area above the $0 \%$ line could be separated.

$$
\left.\mathrm{A}=\mathrm{t} / 2\left(\mathrm{y}_{1}+2 \mathrm{y}_{2}+2 \mathrm{y}_{3}+. .+2 \mathrm{y}_{\mathrm{n}-2}+2 \mathrm{y}_{\mathrm{n}-1}+\mathrm{y}_{\mathrm{n}}\right) \quad \text { (Equation } 1\right)
$$




\section{Statistical analysis}

Analysis of the data was carried out using SPSS Statistics (Version 24.0, IBM, Armonk, NY, USA). Demographic variables were presented by mean and standard deviations and used only as background information about the participants.

To investigate the differences in deformation and deformation rate between the five dorsal neck muscles, a repeated measure analysis of variance (rANOVA) with a post-hoc Bonferroni correction was used. The five muscles were set as a within-subject factors and the time, retrieved from the ultrasound video sequences, was set as a covariate. Withinsubject variance in the rANOVA was corrected with Mauchly or Greenhouse-Geisser depending on sphericity. Effect size of the within-subject effect was reported according to Cohen. ${ }^{27}$ There was a skewness for the deformation values regarding elongation and shortening of the muscles, thus, all measurements were root-square transformed. Level of significance was set at $\mathrm{p}<.05$.

A Kendall's tau-b correlation was used to investigate the interplay between the dorsal neck muscles. Negligible correlations are considered $<0.30$, low correlation $0.30-0.49$, moderate correlation $0.50-0.69$, high correlation $0.70-0.89$, and very high correlation 0.90 $1.00 .^{28}$

\section{Results}

\section{Deformation}

Deformation in left (contralateral) rotation showed significant differences between the muscles in total area $(F(4,76)=3.90, \mathrm{p}=.01)$. Post hoc tests showed higher deformation of the semispinalis capitis compared to the trapezius muscle $(\mathrm{p}=.02)$, but no significant difference between the other muscles. There were no significant differences between the five neck muscles in right (unilateral) rotation $(p=.46$, Table 2 and 3$)$. 


\section{Correlation}

In both left and right rotation, correlations were seen between two muscle pairs in total deformation (left rotation; Trapezius/Semispinalis capitis $r=0.42$ and Spinalis/Multifidus $r=0.41$, right rotation; Trapezius/Semispinalis capitis $r=0.34$ and Semispinalis cervicis/Multifidus $r=0.45$ ). Correlation was also seen between muscles in shortening (left rotation; Semispinalis capitis/Multifidus $\mathrm{r}=-0.41$, right rotation;

Trapezius/Multifidus $r=-0.57$ and Semispinalis capitis/Semispinalis cervicis $r=0.33$ ) and elongation deformation (right rotation; Semispinalis capitis/Semispinalis cervicis $r=$ $0.33)$.

\section{Deformation rate}

There were significant differences in deformation rate (Table 2 and 3) between muscles in both right $(\mathrm{F}(4,76)=10.03, \mathrm{p}<.01)$ and left rotation $(\mathrm{F}(4,76)=9.41, \mathrm{p}<.01)$. In right rotation four muscles (the splenius, semispinalis capitis, semispinalis cervicis and multifidus muscles) showed higher deformation rates than the trapezius muscle $(\mathrm{p}<.01)$. In left rotation three muscles (the splenius, semispinalis capitis, semispinalis cervicis) showed higher deformation rates than the trapezius muscles $(p<.02)$. The semispinalis capitis and semispinalis cervicis $(\mathrm{p}<.03)$ had higher deformation rates than the multifidus muscle $(\mathrm{p}<.03)$.

\section{Correlation}

Correlations in deformation rate were found between all the muscles $(r=0.37-r=0.68)$ except between Trapezius and Semispinalis cervicis in left rotation (Table 4).

\section{Discussion}

Results of this study demonstrate that deformation in the right-sided neck muscles in right rotation was equal in all five muscles during the loaded rotation exercise. In left rotation 
the semispinalis capitis muscle showed higher deformation than the trapezius and there were no other significant differences between the five neck muscles. Deformation rate was lowest in the trapezius muscle during right rotation, and in left rotation both the trapezius and multifidus muscles showed lower rates than the three other muscles.

Earlier research, using speckle tracking analysis, investigated deformation and deformation rate in neck muscles ${ }^{18,21,22,24,25,29}$ during isometric exercises and stabilizing tasks. Real-time ultrasound investigation of the neck muscles has not, to the authors' knowledge, been investigated in a loaded dynamic exercise used in neck rehabilitation. The right-side of the neck muscles were investigated both in right and left rotation. It is implicit that the muscle behavior was different, i.e. in right rotation the muscles was shortening (contraction) from the start of the movement to $70^{\circ}$ rotation and then elongated (passive or eccentric contraction) back to the start position; in left rotation the muscles elongated first and from a stretched position at $70^{\circ}$ rotation, the right-side neck muscles were contracted to move the head back to the start neutral position.

In left rotation, the semispinalis capitis muscle was deformed more than the trapezius muscle. In a biomechanical model study, axial rotation was seen to change the direction of the moment arm (i.e. the perpendicular distance between a joint axis and the force acting on the joint) resulting in a longer moment arm for semispinalis capitis during neck rotation ${ }^{30}$. The increase of the semispinalis capitis moment arm in left rotation could have an influence on muscle mechanical behavior and thereby muscle deformation during the eccentric and concentric phases of the exercise. In other studies using magnet resonance imaging (MRI) or electromyography (EMG) the right-side semispinalis capitis was more involved in right rotation. ${ }^{31,32}$ However, the MRI-study ${ }^{31}$ did not use real-time images and the EMG-study categorized the muscle layers differently from the present study. Moreover, a cadaver study, based on anatomical models, found that right-side semispinalis capitis was one of the prime movers in left rotation ${ }^{33}$ and the present study showed 
significantly higher deformation in the semispinalis capitis compared to the other neck muscles in left rotation. The semispinalis capitis muscle has also be considered to be the prime neck extensor ${ }^{31-34}$ and the quadruped position with a rubber band in the mouth may cause an isometric activation of the muscle to hold the head position against gravity force during the test. Analysis with speckle tracking has also shown that semispinalis capitis had the highest activation of the dorsal neck muscles in resisted isometric contractions in neck extension. ${ }^{35}$ The combination of increased load in extension and an increase of the moment arm in left rotation may contribute to the increase in total activation of the rightside semispinalis capitis.

In right rotation, the deformation for all five muscles was equal and indicates that the exercise was targeted to all the muscles. Findings in earlier studies using MRI show that neither the right-side multifidus or trapezius were involved in right rotation. ${ }^{31}$ Also, research shows that even if the moment arm increases for the right-side multifidus in right rotation, it was relative weak due to its close proximity to the spinal column. ${ }^{36}$ Still images from MRI of neck muscles investigated after an exercise and EMG-studies during a dynamic rotation, showed that right-side semispinalis capitis was involved in right rotation, ${ }^{31,32}$ but this study showed that it was not activated more than the other muscles. However, EMG measures the chemical-electrical changes in muscles and MRI was investigated with still images after activation; i.e. not during real time motion. In contrast, real-time ultrasound measures the muscles' mechanical behavior, the deformation, and deformation rate. Thereby, studies using different methods to investigate muscle function and at different test positions are not directly comparable.

Earlier research regarding deformation rate in prone weighted neck extension showed the highest deformation rate for the multifidus muscle, compared with other dorsal muscles, in individuals with good neck health ${ }^{18,37}$ as well as in patients with whiplash-associated disorders tested in a sitting task when stabilizing the neck during arm lifts. ${ }^{22}$ The 
multifidus muscle has also been shown to have the highest deformation rate in patients who have undergone anterior cervical decompression and fusion for cervical disc disease and healthy controls when tested in isometric contractions in neck extension. ${ }^{23}$ In the present study, the splenius, the semispinalis capitis, and the semispinalis cervicis showed higher deformation rates compared with the trapezius muscle in rotation to both the left and right. In left rotation the semispinalis cervicis and the semispinalis capitis muscles also had higher deformation rates than the multifidus muscle. This finding does not corroborate earlier studies in which the highest deformation rate was found for the multifidus muscle. ${ }^{18,22,23}$ In the present study, it may be possible that the deformation rates in the splenius, the semispinalis capitis and the semispinalis cervicis muscles were higher because these muscles were more activated in the quadruped position against the gravity force with the resistance of the rubber band in combination with stabilizing the neck.

The semispinalis capitis and the trapezius muscle showed a positive correlation in both left and right rotation for the total activation of the muscles, indicating a coordination of these muscles in the quadruped rotation exercise.

In the elongation in left rotation, the results showed a negative correlation between the multifidus and the semispinalis capitis muscle. This means that more elongation in the semispinalis capitis muscle correlates with less elongation in the multifidus muscle. The same was seen between the trapezius muscle and the multifidus muscle in the right rotation. Increasing elongation of the trapezius led to decreasing elongation of the multifidus.

Regarding deformation rate, correlation was seen between almost all muscles in both the left and right rotations. This was in line with earlier findings regarding the interplay of the deformation rate in both ventral ${ }^{24}$ and dorsal ${ }^{22}$ neck muscles during elevation of the arm in controls with good neck health. 
Earlier research ${ }^{22}$ using speckle tracking has shown differences in deformation rates between males and females in both healthy individuals and patients with chronic whiplash- associated disorders where males tend to have higher deformation rates. In the present study there were no differences between sex, and larger studies are needed to find out if there is a difference between males and females, also in the quadruped dynamic loaded neck exercise.

\section{Methodological considerations}

There are some limitations that may have affected the study results. Firstly, more participants may have produced more normally distributed data with fewer outliers. However, for experimental studies investigating dynamic movement using ultrasound and speckle tracking, 20 participants is considered a lot due to the time consuming analysis. It could have been possible to exclude the outliers in the analysis, but earlier research showed a wide range of individual deformation patterns in the muscles of controls with good neck health ${ }^{22}$ with more variations in males. Therefore, excluding extreme outliers may lead to a wrong conclusion regarding normal deformation in a population with good neck health.

Secondly, ultrasound and speckle tracking are methods very dependent of the skills of the user, both to find the anatomical landmarks for correct ultrasound-transducer placement during the data collection, and to place the ROIs manually in the post-processing process. The ultrasound measurements in this study were collected by a medical engineer who has often used ultrasound in research, with help of an experienced PT to identify anatomical landmarks. The post-processing speckle tracking was done by a PT with ten years of experience of ultrasound analyses. Speckle tracking has been validated with good results against force measurement in the biceps brachii muscle. ${ }^{38}$ It has also been proven reliable when measuring left ventricle heart function. ${ }^{39}$ Ultrasound with speckle tracking analysis 
is a non-invasive method of measuring muscle deformation in real-time video sequences which is an important benefit compared to other methods. Also, in contrast to EMG, it is possible to measure changes in muscle length during a movement with speckle tracking.

On the other hand, EMG measures electrical activation, ${ }^{40}$ whereas speckle tracking analysis does not discriminate active from passive deformation of the muscles.

The participants were visually checked for test position, with the chin tucked and slight extension in the lower cervical spine, but not controlled for in other ways during the rotation by the PT. The lack of more precise standardization decreases the statistical power, but the result is clinically relevant and the present dynamic loaded neck exercise has been used in rehabilitation in Sweden for decades.

\section{Conclusions}

The study results indicate equal muscle deformation in all five investigated neck muscles during right rotation. In left rotation, the semispinalis capitis muscle had higher deformation than the trapezius, but the other four muscles were equal deformed. There were low to moderate correlations between the five neck muscles in deformation rate. The quadrupled standing dynamic neck rotation exercise is an exercise that activates all the investigated neck muscles. In future studies, individuals with neck pain should be investigated to improve knowledge about muscle function in in a symptomatic cohort. 


\section{References}

1. Sarquis LM, Coggon D, Ntani G, et al. Classification of neck/shoulder pain in epidemiological research: a comparison of personal and occupational characteristics, disability, and prognosis among 12,195 workers from 18 countries. Pain. 2016;157(5):1028-1036.

2. Hoy DG, Protani M, De R, Buchbinder R. The epidemiology of neck pain. Best Pract Res Clin Rheumatol. 2010;24(6):783-792.

3. Jull G, Sterling M, Falla D, Treleaven J, O'Leary S. Whiplash, headache, and neck pain: research-based directions for physical therapies. 2008.

4. Stanaway J, Afshin A, Gakidou E, et al. Global, regional, and national incidence, prevalence, and years lived with disability for 354 diseases and injuries for 195 countries and territories, 1990-2017: a systematic analysis for the Global Burden of Disease Study 2017. The Lancet. 2018;392(10159):1789-1858.

5. Kleinman N, Patel AA, Benson C, Macario A, Kim M, Biondi DM. Economic burden of back and neck pain: effect of a neuropathic component. Popul Health Manag. 2014;17(4):224-232.

6. O'Leary S, Cagnie B, Reeve A, Jull G, Elliott JM. Is There Altered Activity of the Extensor Muscles in Chronic Mechanical Neck Pain? A Functional Magnetic Resonance Imaging Study. Archives of Physical Medicine and Rehabilitation. 2011;92(6):929-934.

7. $\quad$ Cagnie B, O'leary S, Elliott J, Peeters I, Parlevliet T, Danneels L. Pain-induced Changes in the Activity of the Cervical Extensor Muscles Evaluated by Muscle Functional Magnetic Resonance Imaging. The Clinical Journal of Pain. 2011;27(5):392-397.

8. Gross AR, Paquin JP, Dupont G, et al. Exercises for mechanical neck disorders: A Cochrane review update. Manual Therapy. 2016;24:25-45.

9. Panjabi MM. The stabilizing system of the spine. Part I. Function, dysfunction, adaptation, and enhancement. $J$ Spinal Disord. 1992;5(4):383-389; discussion 397.

10. Falla D, Farina D. Neuromuscular adaptation in experimental and clinical neck pain. Journal of Electromyography and Kinesiology. 2008;18(2):255-261.

11. Elsig S, Luomajoki H, Sattelmayer M, Taeymans J, Tal-Akabi A, Hilfiker R. Sensorimotor tests, such as movement control and laterality judgment accuracy, in persons with recurrent neck pain and controls. A case-control study. Man Ther. 2014;19(6):555-561.

12. Äng OB, Monnier OA, Harms-Ringdahl OK. Neck/Shoulder Exercise for Neck Pain in Air Force Helicopter Pilots: A Randomized Controlled Trial. Spine. 2009;34(16):E544-E551.

13. Peterson GE, Landen Ludvigsson MH, O'Leary SP, et al. The Effect of 3 Different Exercise Approaches on Neck Muscle Endurance, Kinesiophobia, Exercise Compliance, and Patient Satisfaction in Chronic Whiplash. $J$ Manipulative Physiol Ther. 2015;38(7):465-476 e464.

14. Äng B. Neck pain in air force pilots : on risk factors, neck motor function and an exercise intervention. Stockholm, Stockholm : Karolinska institutet; 2007.

15. Peolsson A, Peolsson M, Jull G, S OL. Is there a difference in the pattern of muscle activity when performing neck exercises with a guild board versus a pulley? $J$ Rehabil Med. 2013;45(9):900-905.

16. Hoskins P, Martin K, Thrush A. Diagnostic ultrasound : physics and equipment. Cambridge: Cambridge University Press; 2010.

17. Peolsson, Löfstedt, Vogt, Stenlund, Arndt, Trygg. Modelling human musculoskeletal functional movements using ultrasound imaging. 2010;10(9):11 sidor.

18. Peolsson A, Peolsson M. Longitudinal changes in ventral and dorsal neck muscle layers during loading against gravity in healthy volunteers using speckle tracking. J Manipulative Physiol Ther. 2014;37(4):253-259. 
19. Gronlund C, Claesson K, Holtermann A. Imaging two-dimensional mechanical waves of skeletal muscle contraction. Ultrasound Med Biol. 2013;39(2):360-369.

20. Yoshii Y, Henderson J, Villarraga HR, Zhao C, An KN, Amadio PC. Ultrasound assessment of the motion patterns of human flexor digitorum superficialis and profundus tendons with speckle tracking. J Orthop Res. 2011;29(10):1465-1469.

21. van der Werff R, O'Leary S, Jull G, Peolsson M, Trygg J, Peolsson A. A speckle tracking application of ultrasound to evaluate activity of multilayered cervical muscles. J Rehabil Med. 2014;46(7):662-667.

22. Peterson G, Nilsson D, Peterson S, et al. Changes in Dorsal Neck Muscle Function in Individuals with Chronic Whiplash-Associated Disorders: A Real-Time Ultrasound Case-Control Study. Ultrasound Med Biol. 2016;42(5):1090-1102.

23. Peolsson A, Lofstedt T, Trygg J, Peolsson M. Ultrasound imaging with speckle tracking of cervical muscle deformation and deformation rate: isometric contraction of patients after anterior cervical decompression and fusion for cervical disc disease and controls. Man Ther. 2012;17(6):519-525.

24. Peterson G, Dedering A, Andersson E, et al. Altered ventral neck muscle deformation for individuals with whiplash associated disorder compared to healthy controls - A case-control ultrasound study. Man Ther. 2015;20(2):319327.

25. Peterson G, Nilsson D, Trygg J, et al. Novel insights into the interplay between ventral neck muscles in individuals with whiplash-associated disorders. Sci Rep. 2015;5:15289.

26. Anneli P, Gunnel P, Johan T, David N. Multivariate analysis of ultrasoundrecorded dorsal strain sequences: Investigation of dynamic neck extensions in women with chronic whiplash associated disorders. Scientific Reports. 2016;6.

27. Field A. Discovering statistics using SPSS : (and sex and drugs and rock ' $n$ ' roll). 3. ed. ed. Los Angeles ; London: Los Angeles ; London : SAGE; 2009.

28. Mukaka MM. Statistics Corner: A guide to appropriate use of Correlation coefficient in medical research. Malawi Med J. 2012;24(3):69-71.

29. Peolsson A, Marstein E, McNamara T, et al. Does posture of the cervical spine influence dorsal neck muscle activity when lifting? Man Ther. 2014;19(1):32-36.

30. Vasavada AN, Li S, Delp SL. Influence of muscle morphometry and moment arms on the moment-generating capacity of human neck muscles. Spine.

1998;23(4):412-422.

31. Conley MS, Meyer RA, Bloomberg JJ, Feeback DL, Dudley GA. Noninvasive analysis of human neck muscle function. Spine. 1995;20(23):2505.

32. Mayoux-Benhamou M, Revel M, Vallee C. Selective electromyography of dorsal neck muscles in humans. Experimental Brain Research. 1997;113(2):353-360.

33. Ackland DC, Merritt JS, Pandy MG. Moment arms of the human neck muscles in flexion, bending and rotation. Journal of Biomechanics. 2011;44(3):475-486.

34. Vasavada NA, Li LS, Delp LS. Influence of Muscle Morphometry and Moment Arms on the Moment-Generating Capacity of Human Neck Muscles. Spine. 1998;23(4):412-422.

35. Peolsson A, Brodin L-Å, Peolsson M. A tissue velocity ultrasound imaging investigation of the dorsal neck muscles during resisted isometric extension. Manual Therapy. 2010;15(6):567-573.

36. Anderson SJ, Hsu WA, Vasavada NA. Morphology, Architecture, and Biomechanics of Human Cervical Multifidus. Spine. 2005;30(4):E86-E91.

37. Rahnama, Peterson, Kazemnejad, Trygg, Peolsson. Alterations in the Mechanical Response of Deep Dorsal Neck Muscles in Individuals Experiencing WhiplashAssociated Disorders Compared to Healthy Controls : An Ultrasound Study. 2018;97(2):75-82.

38. Lopata RGP, van Dijk JP, Pillen S, et al. Dynamic imaging of skeletal muscle contraction in three orthogonal directions. Journal of applied physiology (Bethesda, Md : 1985). 2010;109(3):906.

39. Brown J, Jenkins C, Marwick TH. Use of myocardial strain to assess global left ventricular function: A comparison with cardiac magnetic resonance and 3- 
dimensional echocardiography. American Heart Journal. 2009;157(1):102.e101102.e105.

40. Lo Martire R, Gladh K, Westman A, Äng B. Neck Muscle EMG-Force Relationship and Its Reliability During Isometric Contractions. Sports Medicine - Open.

2017;3(1):1-10. 


\section{Table 1}

Demographic data of the participants, $\mathrm{N}=20$.

Age (years; mean and SD)

$27.6(7.28)$

Height (cm; mean and SD)

$174.9(8.60)$

Weight (kg; mean and SD)

$69.4(11.06)$

Physical activity level ${ }^{1}$ (mean and

SD)

Training level ${ }^{1}$ (mean and SD)

$3.30(0.73)$

Neck Disability Index ${ }^{2}$ (mean and SD)

${ }^{1} 1$ - inactivity, 2 - low activity, 3 - moderate activity, 4 - high activity

${ }^{2}$ Neck Disability Index (0-100\%) based on 10 items. Higher scores represent higher disability

\section{Table 2}

Muscle deformation ( $\%$ change in length) and deformation rate ( $\%$ deformation $/ \mathrm{s})$ during neck rotation exercise. The five neck muscles are: Trapezius (Tr), Spinalis (Sp), Semispinalis capitis (Sca), Semispinalis cervicis (Scer), and Multifidus (Mf). Total area represents the sum of elongations and shortenings of the muscles. Displays significance level (p) and effect size (ES). Data were analyzed with repeated measure analysis of variance (rANOVA).

Deformation

\begin{tabular}{|c|c|c|c|c|c|c|c|c|c|c|c|}
\hline \multicolumn{12}{|c|}{ Total area } \\
\hline \multicolumn{7}{|c|}{ Left rotation } & \multicolumn{5}{|c|}{ Right rotation } \\
\hline \multirow[b]{4}{*}{$\operatorname{Tr}$} & \multirow[t]{3}{*}{ Mean } & \multicolumn{2}{|c|}{$\begin{array}{c}95 \% \text { Confidence } \\
\text { interval }\end{array}$} & $\mathrm{p}$ & ES & & Mean & \multicolumn{2}{|c|}{$\begin{array}{c}95 \% \text { Confidence } \\
\text { interval }\end{array}$} & $\mathrm{p}$ & ES \\
\hline & & $\begin{array}{l}\text { Lower } \\
\text { bound }\end{array}$ & $\begin{array}{l}\text { Upper } \\
\text { bound }\end{array}$ & \multirow{7}{*}{$<0.01$} & \multirow{7}{*}{0.17} & \multirow[b]{3}{*}{$\operatorname{Tr}$} & \multirow[b]{3}{*}{4.56} & $\begin{array}{l}\text { Lower } \\
\text { bound }\end{array}$ & $\begin{array}{l}\text { Upper } \\
\text { bound }\end{array}$ & \multirow{8}{*}{0.46} & \multirow{7}{*}{0.13} \\
\hline & & & & & & & & & \multirow[b]{2}{*}{5.22} & & \\
\hline & 4.31 & 3.68 & 4.93 & & & & & 3.90 & & & \\
\hline $\mathrm{Sp}$ & 4.91 & 4.07 & 5.77 & & & $\mathrm{Sp}$ & 4.52 & 3.99 & 5.11 & & \\
\hline Sca & 5.90 & 4.94 & 6.86 & & & Sca & 4.87 & 4.06 & 5.68 & & \\
\hline Scer & 4.81 & 4.19 & 5.44 & & & Scer & 5.31 & 4.12 & 6.51 & & \\
\hline Mf & 4.48 & 3.87 & 5.09 & & & Mf & 4.68 & 4.01 & 5.34 & & \\
\hline \multicolumn{11}{|c|}{ Shortening } & \\
\hline \multicolumn{6}{|c|}{ Left rotation } & & \multicolumn{5}{|c|}{ Right rotation } \\
\hline & \multirow[t]{2}{*}{ Mean } & \multicolumn{2}{|c|}{$\begin{array}{c}95 \% \text { Confidence } \\
\text { interval }\end{array}$} & $\mathrm{p}$ & ES & & Mean & \multicolumn{2}{|c|}{$\begin{array}{c}95 \% \text { Confidence } \\
\text { interval } \\
\end{array}$} & $\mathrm{p}$ & ES \\
\hline & & $\begin{array}{l}\text { Lower } \\
\text { bound }\end{array}$ & $\begin{array}{l}\text { Upper } \\
\text { bound }\end{array}$ & & & & & $\begin{array}{l}\text { Lower } \\
\text { bound }\end{array}$ & $\begin{array}{l}\text { Upper } \\
\text { bound }\end{array}$ & & \\
\hline
\end{tabular}


$0.53 \quad 0.14$

$\begin{array}{llll}\text { Tr } & 3.09 & 2.20 & 3.97 \\ \text { Sp } & 3.32 & 2.18 & 4.46 \\ \text { Sca } & 3.76 & 2.32 & 5.20 \\ \text { Scer } & 2.63 & 1.54 & 3.72 \\ \text { Mf } & 2.68 & 1.70 & 3.67\end{array}$

$\begin{array}{llll}\text { Tr } & 1.26 & 0.46 & 2.06 \\ \text { Sp } & 2.17 & 1.24 & 3.09 \\ \text { Sca } & 2.20 & 1.15 & 3.09 \\ \text { Scer } & 2.61 & 1.32 & 3.91 \\ \text { Mf } & 2.64 & 1.66 & 3.62\end{array}$

$0.28 \quad 0.06$

Elongation

\begin{tabular}{|c|c|c|c|c|c|c|c|c|c|c|c|}
\hline \multicolumn{6}{|c|}{ Left rotation } & & & \multicolumn{4}{|c|}{ Right rotation } \\
\hline & Mean & \multicolumn{2}{|c|}{$\begin{array}{c}95 \% \text { Confidence } \\
\text { interval } \\
\end{array}$} & $\mathrm{p}$ & ES & & Mean & \multicolumn{2}{|c|}{$\begin{array}{c}95 \% \text { Confidence } \\
\text { interval } \\
\end{array}$} & $\mathrm{p}$ & ES \\
\hline & & $\begin{array}{l}\text { Lower } \\
\text { bound }\end{array}$ & $\begin{array}{l}\text { Upper } \\
\text { bound }\end{array}$ & \multirow{7}{*}{0.58} & \multirow{7}{*}{0.16} & & & $\begin{array}{l}\text { Lower } \\
\text { bound }\end{array}$ & $\begin{array}{l}\text { Upper } \\
\text { bound }\end{array}$ & \multirow{8}{*}{0.64} & \multirow{8}{*}{0.03} \\
\hline & & & & & & & & & & & \\
\hline $\operatorname{Tr}$ & 2.21 & 1.46 & 2.97 & & & $\operatorname{Tr}$ & 3.88 & 3.01 & 4.74 & & \\
\hline $\mathrm{Sp}$ & 2.18 & 1.01 & 3.35 & & & $\mathrm{Sp}$ & 3.26 & 2.42 & 4.10 & & \\
\hline Sca & 2.96 & 1.70 & 4.23 & & & Sca & 3.55 & 2.44 & 4.66 & & \\
\hline Scer & 3.02 & 2.10 & 3.94 & & & Scer & 3.50 & 2.13 & 4.86 & & \\
\hline Mf & 2.43 & 1.42 & 3.43 & & & Mf & 2.84 & 1.82 & 3.87 & & \\
\hline \multicolumn{10}{|c|}{ Deformation rate } & & \\
\hline \multicolumn{6}{|c|}{ Left rotation } & & & \multicolumn{4}{|c|}{ Right rotation } \\
\hline & Mean & \multicolumn{2}{|c|}{$\begin{array}{c}95 \% \text { Confidence } \\
\text { interval }\end{array}$} & $\mathrm{p}$ & ES & & Mean & \multicolumn{2}{|c|}{$\begin{array}{c}95 \% \text { Confidence } \\
\text { interval }\end{array}$} & $\mathrm{p}$ & ES \\
\hline & & $\begin{array}{l}\text { Lower } \\
\text { bound }\end{array}$ & $\begin{array}{l}\text { Upper } \\
\text { bound } \\
\end{array}$ & & & & & $\begin{array}{l}\text { Lower } \\
\text { bound }\end{array}$ & $\begin{array}{l}\text { Upper } \\
\text { bound }\end{array}$ & & \\
\hline & & & & $<0.00$ & 0.58 & & & & & $<0.00$ & 0.80 \\
\hline $\operatorname{Tr}$ & 2.98 & 2.56 & 3.39 & & & $\operatorname{Tr}$ & 2.69 & 2.39 & 2.99 & & \\
\hline $\mathrm{Sp}$ & 3.52 & 3.12 & 3.91 & & & $\mathrm{Sp}$ & 3.42 & 3.08 & 3.76 & & \\
\hline Sca & 3.63 & 3.18 & 4.07 & & & Sca & 3.44 & 3.07 & 3.82 & & \\
\hline Scer & 3.70 & 3.33 & 4.08 & & & Scer & 3.36 & 2.99 & 3.72 & & \\
\hline Mf & 3.26 & 2.87 & 3.66 & & & Mf & 3.20 & 2.80 & 3.59 & & \\
\hline
\end{tabular}




\section{Table 3}

Differences in muscle deformation and deformation rate between the Trapezius ( $\mathrm{Tr}$ ), the Spinalis (Sp), the Semispinalis capitis (Sca), the Semispinalis cervicis (Scer) and the Multifidus (Mf) muscles. Data were analyzed with post-hoc Bonferroni correction.

\begin{tabular}{|c|c|c|c|c|c|c|c|}
\hline & & & & & & $\begin{array}{r}95 \% \text { C } \\
\text { in }\end{array}$ & $\begin{array}{l}\text { idence } \\
\text { al }\end{array}$ \\
\hline & & & & $\begin{array}{c}\text { Mean } \\
\text { difference }\end{array}$ & $\mathrm{p}$ & $\begin{array}{l}\text { Lower } \\
\text { bound }\end{array}$ & $\begin{array}{l}\text { Upper } \\
\text { bound }\end{array}$ \\
\hline Deformation total area & Left & & & & & & \\
\hline & & $\operatorname{Tr}$ & $\mathrm{Sp}$ & -0.62 & 1.00 & -2.11 & 0.88 \\
\hline & & & Sca & -1.60 & .02 & -3.02 & -0.17 \\
\hline & & & Scer & -0.51 & 1.00 & -1.94 & 0.93 \\
\hline & & & Mf & -0.18 & 1.00 & -1.23 & 0.88 \\
\hline & & $\mathrm{Sp}$ & Sca & -0.98 & 1.00 & -2.83 & 0.87 \\
\hline & & & Scer & 0.11 & 1.00 & -1.32 & 1.54 \\
\hline & & & Mf & 0.44 & 1.00 & -0.73 & 1.61 \\
\hline & & Sca & Scer & 1.09 & .30 & -0.38 & 2.56 \\
\hline & & & Mf & 1.42 & .07 & -0.08 & 2.92 \\
\hline & & Scer & Mf & -0.33 & 1.00 & -0.76 & 1.42 \\
\hline Deformation rate & Left & & & & & & \\
\hline & & $\operatorname{Tr}$ & $\mathrm{Sp}$ & -0.54 & .01 & -0.99 & -0.09 \\
\hline & & & Sca & -0.65 & .02 & -1.21 & -0.09 \\
\hline & & & Scer & -0.73 & .00 & -1.23 & -0.22 \\
\hline & & & Mf & -0.29 & .47 & -0.71 & 0.14 \\
\hline & & $\mathrm{Sp}$ & Sca & -0.11 & 1.00 & -0.54 & 0.32 \\
\hline & & & Scer & -0.19 & 1.00 & -0.62 & 0.25 \\
\hline & & & Mf & 0.25 & .40 & -0.11 & 0.62 \\
\hline & & Sca & Scer & -0.08 & 1.00 & -0.46 & 0.31 \\
\hline & & & Mf & 0.36 & .02 & 0.04 & 0.69 \\
\hline & & Scer & Mf & 0.44 & .03 & 0.03 & 0.85 \\
\hline Deformation rate & Right & & & & & & \\
\hline & & $\operatorname{Tr}$ & $\mathrm{Sp}$ & -0.73 & .00 & -1.08 & -0.38 \\
\hline & & & Sca & -0.75 & .00 & -1.17 & -0.33 \\
\hline & & & Scer & -0.69 & .00 & -1.10 & -0.24 \\
\hline & & & Mf & -0.51 & .01 & -0.90 & -0.11 \\
\hline & & $\mathrm{Sp}$ & Sca & -0.03 & 1.00 & -0.57 & 0.52 \\
\hline & & & Scer & 0.06 & 1.00 & -0.37 & 0.49 \\
\hline & & & Mf & 0.22 & 1.00 & -0.28 & 0.72 \\
\hline & & Sca & Scer & 0.09 & 1.00 & -0.40 & 0.57 \\
\hline & & & Mf & 0.25 & .32 & -0.09 & 0.59 \\
\hline & & Scer & Mf & 0.16 & 1.00 & -0.32 & 0.65 \\
\hline
\end{tabular}




\section{Table 4}

Correlation between the Trapezius (Tr), the Spinalis (Sp), the Semispinalis capitis (Sca), the Semispinalis cervicis (Scer), and the Multifidus (Mf) muscles in deformation (total deformation, shortening and elongation) and deformation rate. Data were analyzed with Kendall's tau-b correlation.

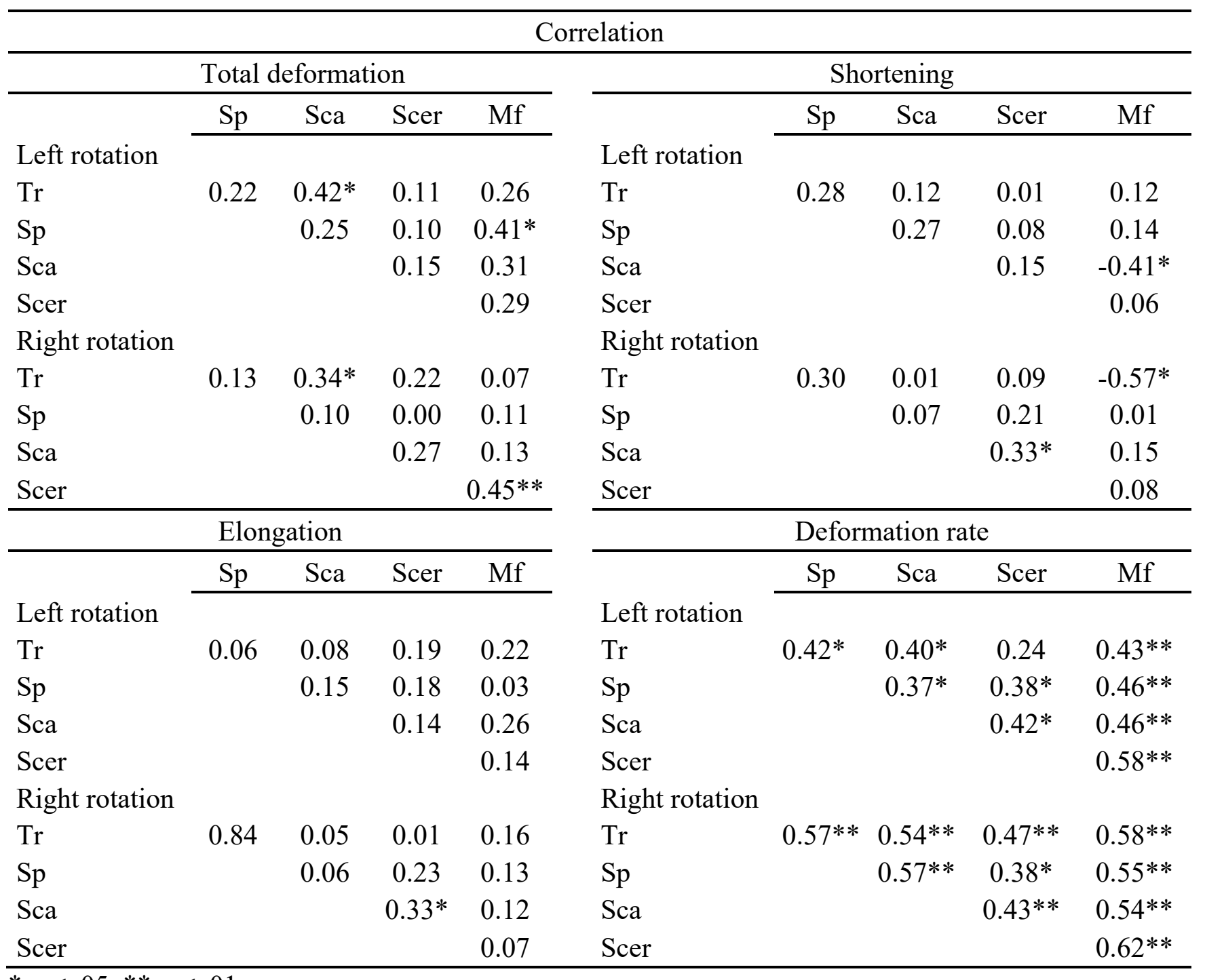




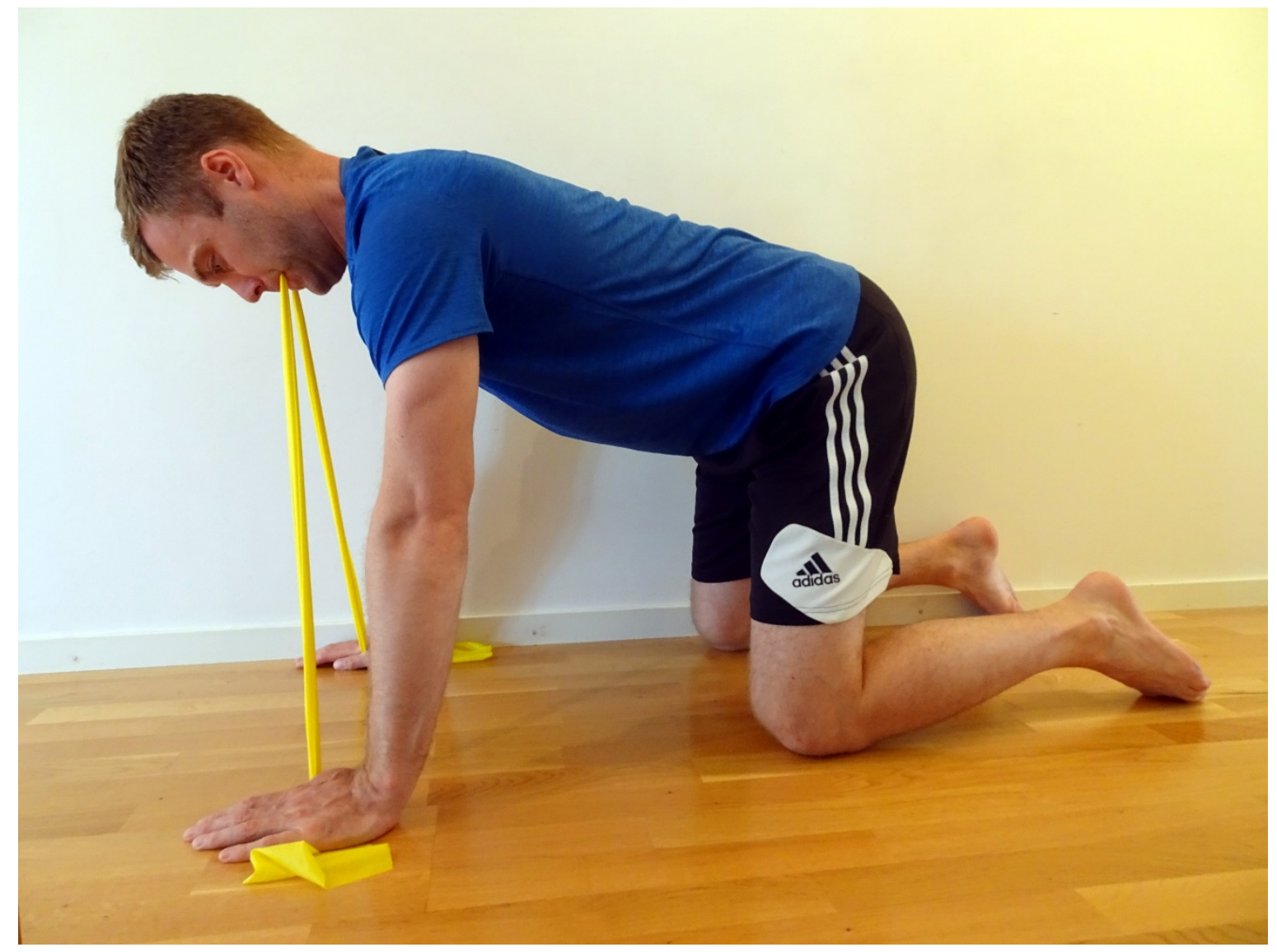

Figure 1. Starting position of the dynamic rotation exercise.

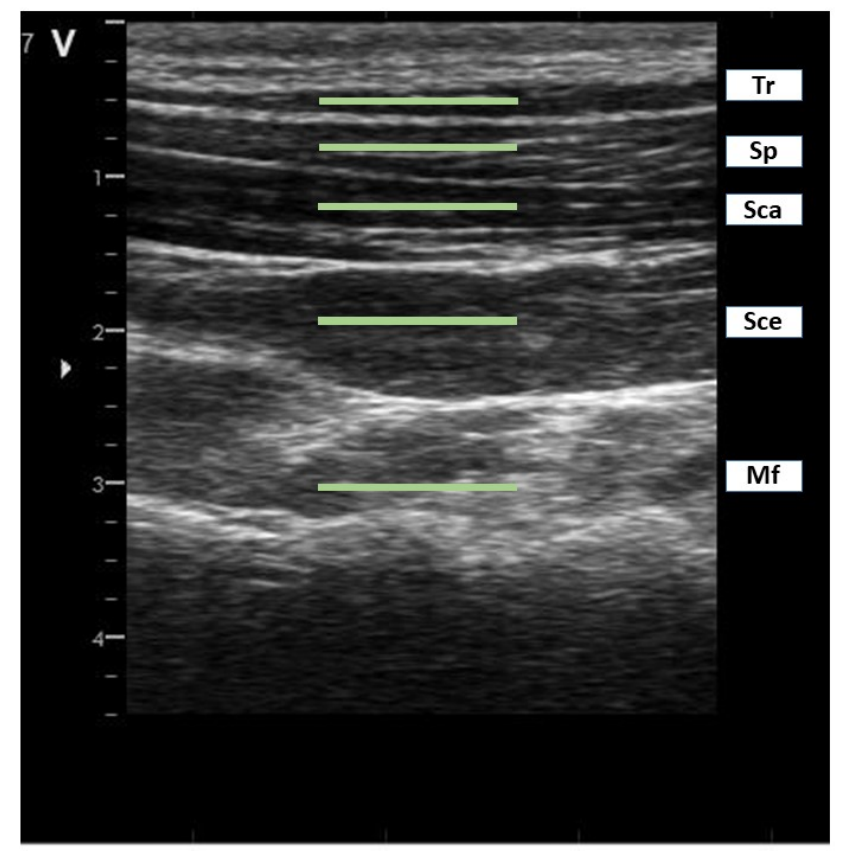

Figure 2. Ultrasound image of the dorsal neck muscles

The image shows a longitudinal ultrasound B-mode projection. The specific muscles are trapezius (Tr), splenius (Sp), semispinalis capitis (Sca), semispinalis cervicis (Sce), 
multifidus (Mf). One region of interest (ROI; each indicated as a green line) was selected in each muscle for post-process speckle tracking analysis.

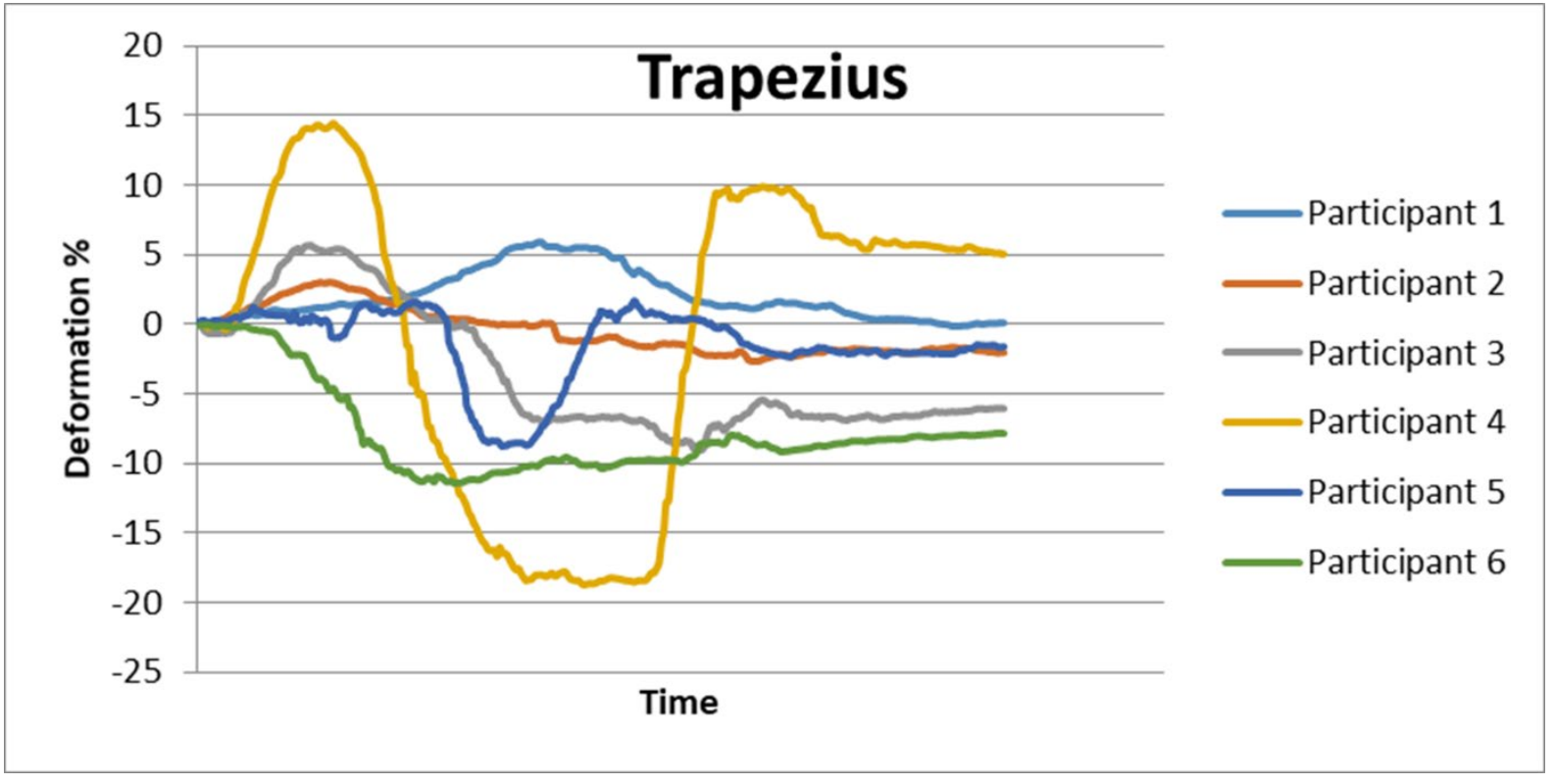

Figure 3. The deformation curves of the trapezius muscle in six participants during rotation to the left. A positive value (area over the curve) indicated elongation of the muscle; a negative value (area under the curve) indicated shortening of the muscle. The total sum of area with both positive and negative values represents the total deformation. The position where the line crosses the 0 -mark line indicates changes in the muscle from elongation to shortening, or vice versa. 